\title{
The Norman Site Excavations Near Wagoner, Oklahoma
}

\section{J. Joe Finkelstein \\ Unknown}

Follow this and additional works at: https://scholarworks.sfasu.edu/ita

Part of the American Material Culture Commons, Archaeological Anthropology Commons, Environmental Studies Commons, Other American Studies Commons, Other Arts and Humanities Commons, Other History of Art, Architecture, and Archaeology Commons, and the United States History Commons

Tell us how this article helped you.

This Article is brought to you for free and open access by the Center for Regional Heritage Research at SFA ScholarWorks. It has been accepted for inclusion in Index of Texas Archaeology: Open Access Gray Literature from the Lone Star State by an authorized editor of SFA ScholarWorks. For more information, please contact cdsscholarworks@sfasu.edu. 


\section{The Norman Site Excavations Near Wagoner, Oklahoma}

Creative Commons License

(c) (i) (8)

This work is licensed under a Creative Commons Attribution-NonCommercial 4.0 International License 


\title{
THE NORMAN SITE EXCAVATIONS NEAR WAGONER, OKLAHOMA
}

\author{
J. Joe Finkelstein
}

The Norman site is seven miles southeast of Wagoner, Wagoner County, Okla., on State Highway 51. It is on the upper terraces on the west side of Grand River just north of the approach to the new bridge. Principal mound is a double unit; the larger mound, clearly visible from the highway, is conical, $27^{\prime}$ high and $90^{\prime}$ in diameter; the low mound, on the north, is circular, $7^{\prime}$ high and $100^{\prime}$ in diameter; a low, broad saddle $12^{\prime}$ long connects the 2 mounds (Figure A - map, Mounds I-1 and I-2; ed. note $I^{2}$ ). An extensive habitation

1 The statewide program of archaeological research conducted by the University of Oklahoma with the support of the federal relief administrations was inaugurated at the beginning of 1934 when, with funds made available by the CWA, a small project was started on the Norman site. Later in the same year, with the aid of FERA allotments, the program was expanded to include a project in the Panhandle. In 1936, with WPA assistance, the program was enlarged to its present scope. From its inception, the program has been under the direction of Dr. Forrest E. Clements, state director of archaeology at the University of Oklahoma. The three seasons ' work at Wagoner were under the field supervision of the writer, with the exception of the last month of operations, which were supervised by H.R. Antle.

2 The figure numbers from the original publication have been retained here. The map did not have a figure number in the original; thus, it became Figure A. area, Unit IV, extends to the north and northeast of Mound I-2. Unit II was also a double unit; the larger mound was originally conical, $70^{\prime}$ in diameter and probably $10^{\prime}$ high. It was only $6.5^{\prime}$ high when excavated, owing to a large pit previously dug from the apex. The smaller mound, on the north, was circular, 2.5' high and $45^{\prime}$ in diameter. The edges of the two mounds overlapped somewhat. Unit III is a low circular mound $7^{\prime}$ high and $110^{\prime}$ in diameter. Unit VI is a low, circular mound $1.5^{\prime}$ high and $45^{\prime}$ in diameter. Unit II was completely excavated; approximately one third of Unit II, a portion of Mound I-2 and a portion of the habitation area were also excavated.

\section{Mounds II-1 \& II-2}

Unit II was constructed near the south end of the second terrace, which here dips gradually toward swampy ground. Excavation was carried to a stratum of river gravel which lay from 3 " to 8 " beneath the present surface of the field. A 3" layer of black humic soil lay on the gravel under Mound 2, but was absent under Mound I. There was no stratification within the two mounds; the fill consisted of humus, subsoil and gravel from the surrounding area and occasional loads of red and yellow clay and hard, gray, ashy dirt. 


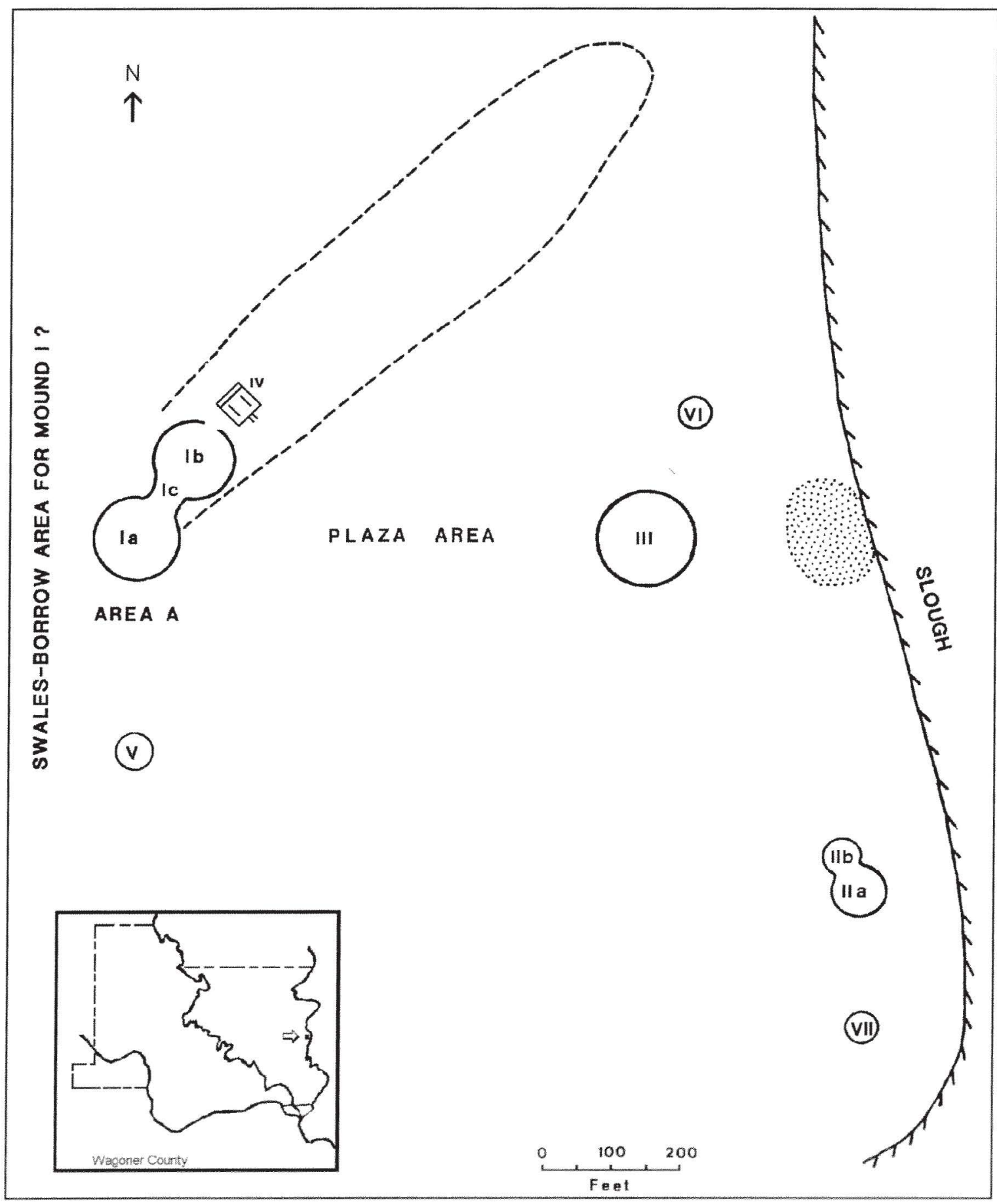

Figure A. Map of the Norman site (34WG2), Wagoner County, Oklahoma (adapted from Finkelstein 1940). 
There were no surface indications of a habitation area in the vicinity, although the mound fill contained midden material. The digging of graves for two modern burials where the mounds overlapped has so disturbed the area it was impossible to determine the sequence of construction of the two mounds. The burial complex is common to both; save for minor differences in artifact types and absence of some traits in. the small mound, the material culture complex is practically identical.

Both mounds were accretive burial mounds. The 71 burials in the large mounds were distributed throughout, from base to within $10^{\prime \prime}$ of the surface; the nine in the low mound were on and just above the base of the mound. Sixty-nine of the burials were bundle, skeletal remains consisting of never more than a few fragments of long bone and several teeth; in 35 instances there was no bone remaining, the presence of a complete pottery vessel, a set of earplugs or a burial basin being considered evidence of a burial. This type of burial was found throughout both mounds, at all levels.

The basins, seven in number, were shallow, circular depressions 2 " to 4 " deep and $2.5^{\prime}$ to $3^{\prime}$ in diameter. These were restricted to the floor and lower levels of Mound I and the floor of Mound 2. Absence of these basins in the upper levels of the large mound would suggest the discontinuance of this form of grave preparation, provided it could be proved the small mound is contemporaneous with the earlier phases of the large mound. Three of the basins had been lined with

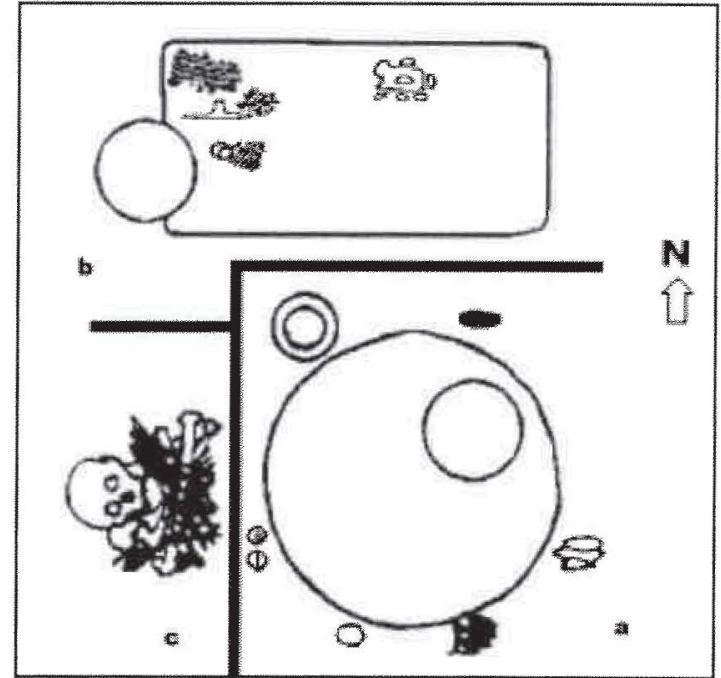

Figure 10. Some burials from Mounds $I-1$ and $1-2$

red clay and fire hardened. Four contained the fragmentary remains of bundle burials. One unfired basin containing no bone remains was accompanied by an unusual quantity of beigabe (Fig. 10,a). One bundle burial was in a pit definitely originating at the surface of the last building phase. The pit was $10^{\prime \prime}$ deep slightly larger in diameter; there was no associated beigabe.

There were five piles of six to 12 large stone slabs in the large mound. There were burials under three of these cairns, but the association is questionable as the bone was from $2^{\prime}$ to $3^{\prime}$ below the stones and there was no evidence of pits beneath the structures. One of these three was a bundle burial.

Three cremation burials were in the southwest quarter of Mound I, associated with the early building period. Of the two cremations in jars, one was on the mound floor and the other was 2 ' above the floor. 
One consisted of charred bone fragments placed in and under two small jars; in the other the few bone fragments were placed in a single small jar. Each was under one end of a stone cairn. The cremation in the prepared basin was on the mound floor. The basin was clay-lined and the body was either cremated in situ, or elsewhere and the ashes of both bone and wood deposited in the previously fired basin.

One deposition in Mound I was made on a thick layer of bark 4' long by 2 ' wide. Although no bone remained, the quantity and placement of associated beigabe marks this a unique form of interment (Fig. 10, b). This burial was associated with an intermediate building phase. The remaining seven burials were modern, interred in pine coffins, secured with old style squared nails.

Thirty four of the 46 bundle burials containing beigabe were related through common pottery types, stone earplugs, double-stem stone pipes, projectile points and copper plates. The actual artifact associations are indicated on the Beigabe and Burial Relationship Table (Table 1). The four bundle burials in basins were related through common pottery types and earplugs, and were related to the common bundle burials through the same artifact types. The burial on the bark carpet was related to the bundle burial complex through earplugs, double-stem pipe and projectile points; to the basin complex through earplugs, projectile points and large, circular, green clay discs.

Although a number of the burials contained no beigabe, 54 were accompanied by at least a single pottery vessel or a set of earplugs. Burial associations are indicated on the Beigabe and Burial Relationship Table. Projectile points were placed or strewn along the north or west side of the burial; all other beigabe was usually placed on the east or south side.

POTTERY: Pottery has been classified on the basis of vessel shape and paste texture into four wares. Predominant vessel shape is the jar with wide mouth, short and slightly flaring rim, circular base. Fig. 1, a, indicates the range of forms. Aberrant forms have globular body, no rim (includes cups), high rim, round base, square base (Fig. 1, e-f). A unique jar is supported by four solid columnar legs resting on a flat square base (Fig. 1, d). Both strap and loop handles, the latter riveted to the vessel wall, are common; both types often have a simple or compound knob projecting upward from the lip. This vessel shape occurs in two wares: A - a thin, flaky, porous ware, predominantly fine shell tempered; and B - a thicker, coarse, compact ware, tempered with shell or grit or untempered. There is a paste gradation from one ware to the other, but the majority of the pottery is classifiable as either one ware or the other. The color range in ware $\mathrm{A}$ is browns to grays; in ware $\mathrm{B}$, browns to yellow. Both exterior and interior are smoothed, ware B frequently having a slightly burnished surface. Decoration is rare on vessels of this group. Round and elongated applique knobs around the shoulder is the most common technique. Incised or nail-punctate vertical lines on 


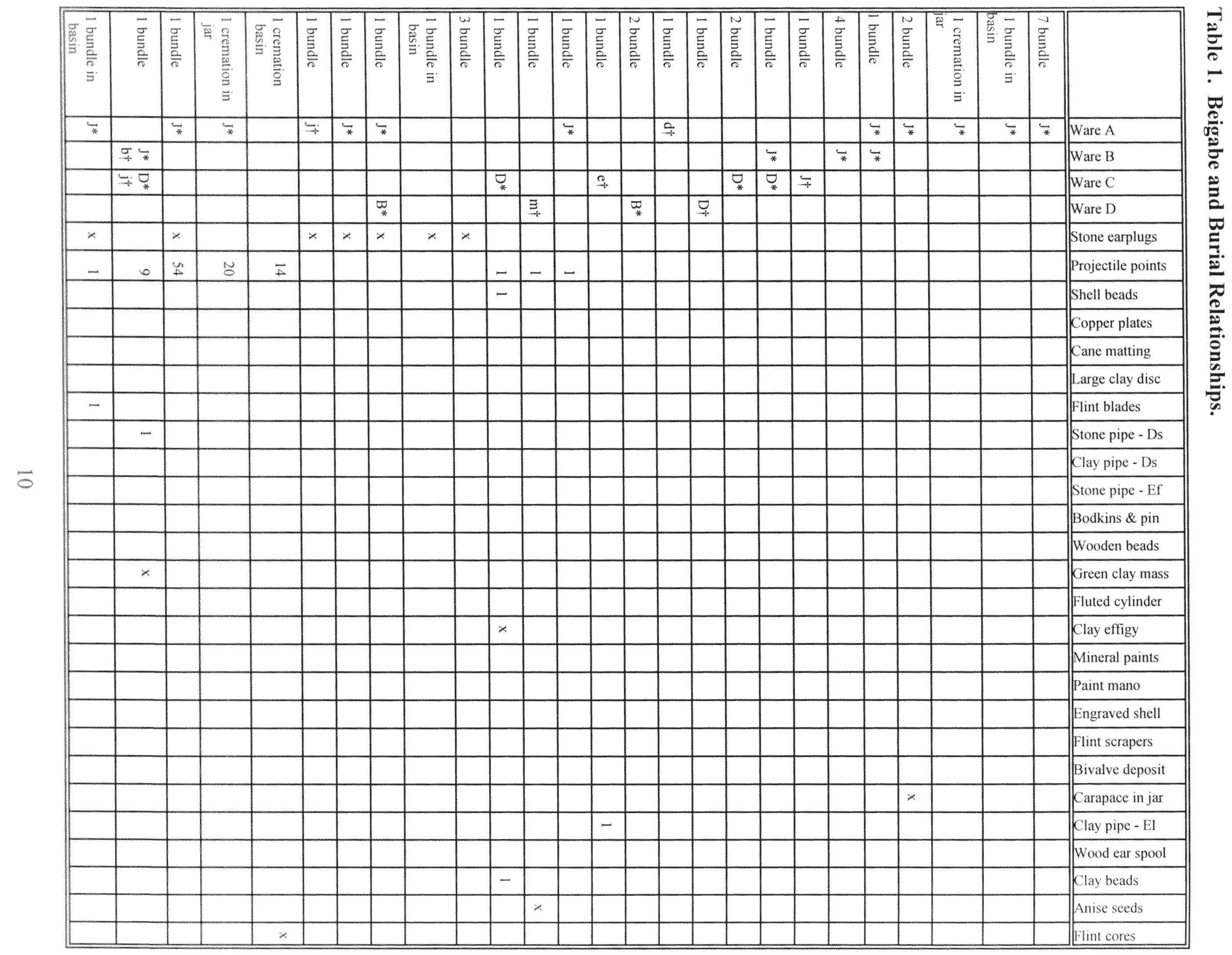


Table 1 (continued). Beigabe and Burial Relationships.

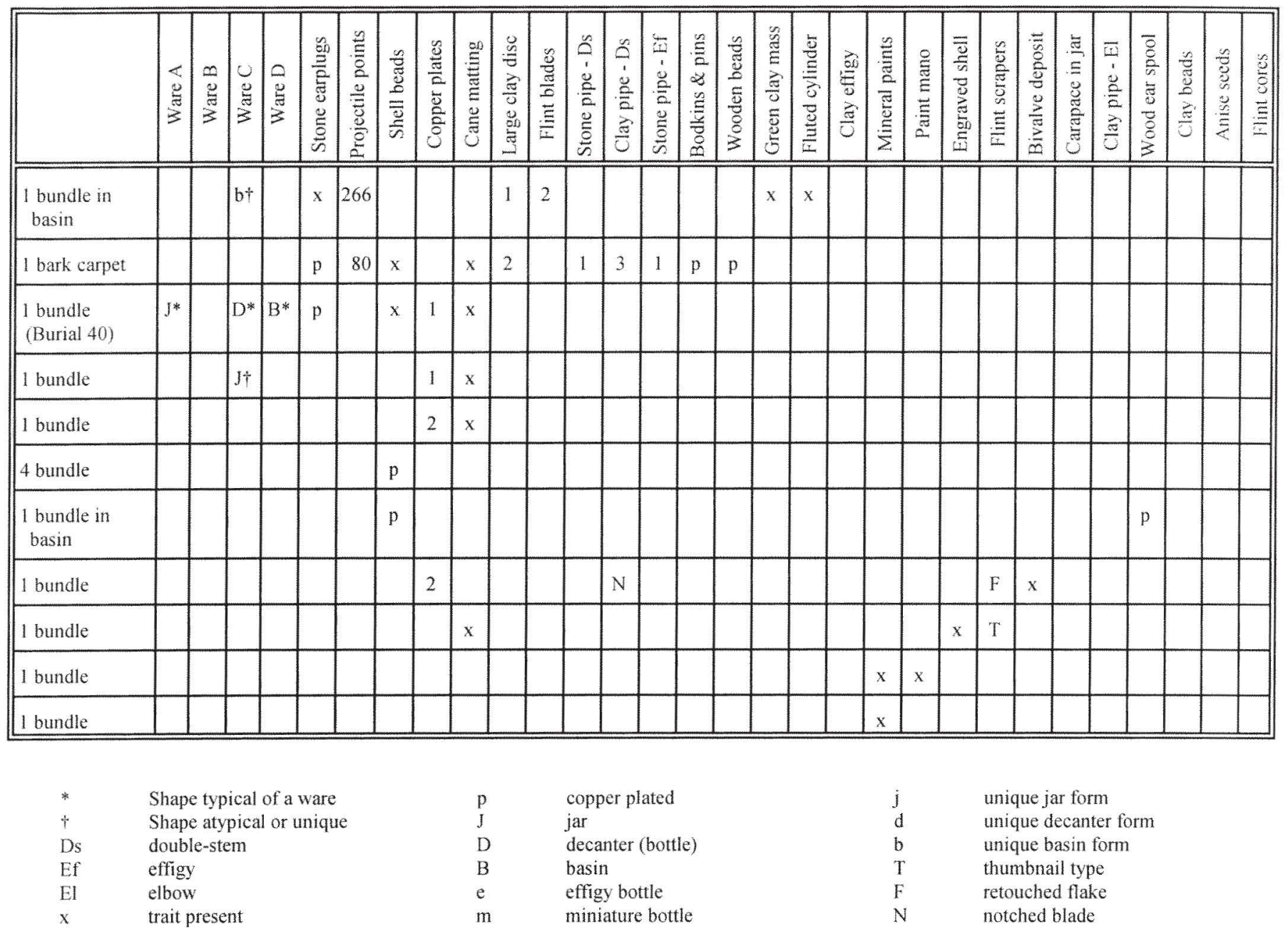

NOTE: Beigabe as used in this chart refers to those objects placed with or by a burial and no distinction is made between intentional and unintentional beigabe.

the full length of the body also occur. Vessels of this group range from 0.5 pint to more than 1 gallon capacity. A unique form in ware $\mathrm{A}$ is a round-bottom bottle with annular base and horizontal flange around base of neck (Fig. 1, i). A unique form in war $B$ is a basin with flaring sides, notched lip (Fig. 1, h).

The bottle shape varies from a slightly flattened to a slightly elongated globe, with flat base and tall, slender neck (Fig. $1, \mathrm{~b})$. The paste texture of this group, ware $\mathrm{C}$, is generally compact and hard. Temper is fine shell, occasionally grit or untempered. Surface is polished to highly burnished. Colors range from dark redbrown to buff. Some bottles are slipped, the slip color ranging from red to bright orange. Many bottles are decorated with incised and engraved concentric circles, cross-hachured semicircles, leaf motif, 


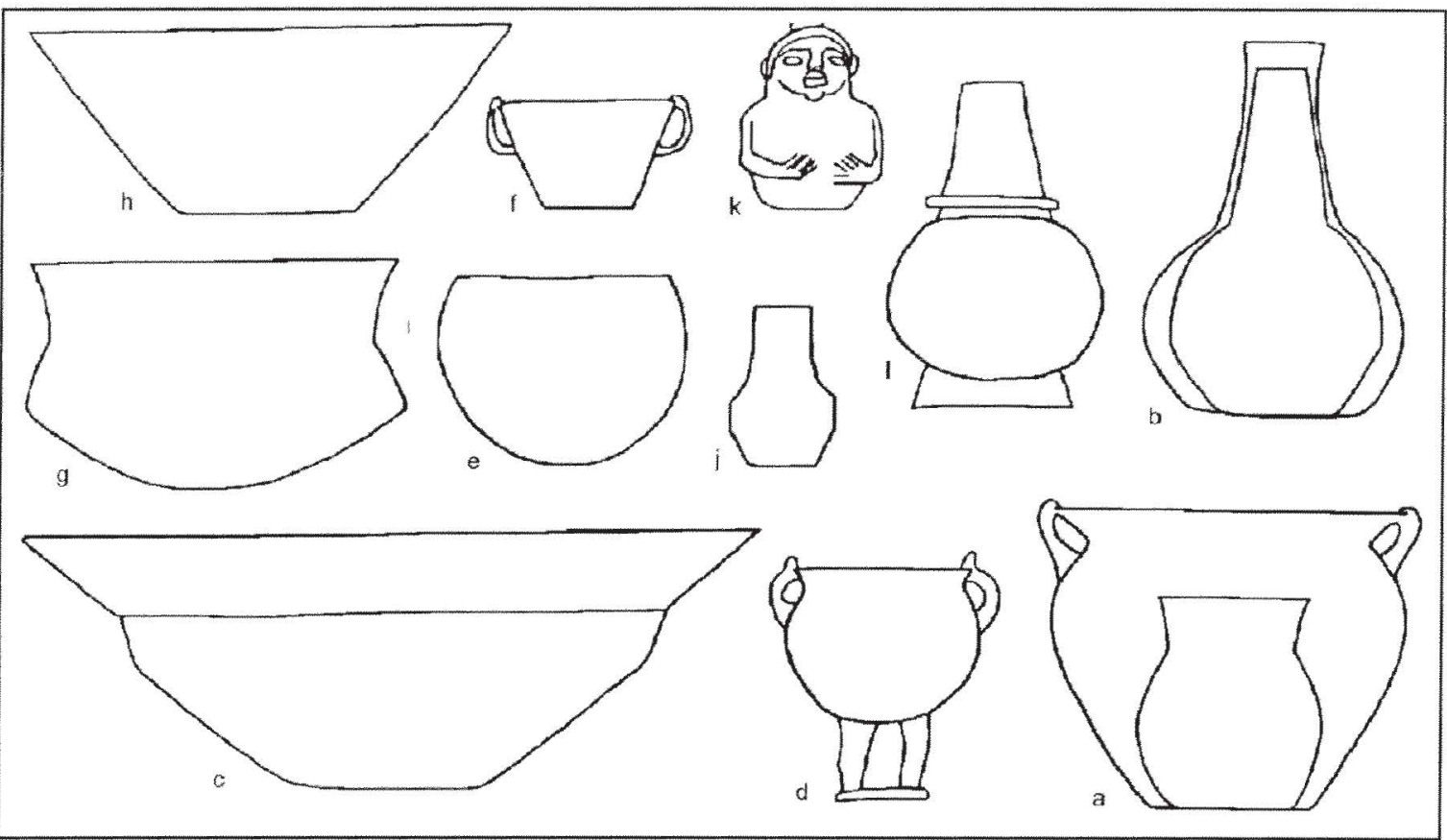

Figure 1. Some vessel forms from the Norman site (34WG2), Wagoner County, Oklahoma. Not to scale.

paneling, and nail-punctate vertical lines. The design element occurs on the body in either three or four units, usually within panels. The neck if occasionally decorated with zig-zag lines or grids. Red paint is frequently found rubbed into the lines. Bottles average slightly more than one quart capacity. A unique bottle form is a small human effigy with orifice at back of head (Fig. 1, k). A unique shape in this ware is a large basin having a round base, incurving shoulder and wide, flaring rim (Fig. 1, g). Also unique are: a small jar with exceptionally high rim (Fig, 1, a); and a jar with square base and applique ridge design, suggesting basketweave, on the shoulder.

Typical of the basin group are: 1) a large, deep basin, the lower portion flaring broadly from the circular, flat base and the upper portion continuing upward almost vertically; and 2) a variation of this form which has a broad, flaring rim added (Fig. $1, \mathrm{c})$. These basins are made of a thick, porous ware, heavily impregnated with coarse shell temper. Both exterior and interior of this ware D are red-slipped. This slip frequently flakes away from the surface, which is brown to buff in color. There is no decoration on this group. Capacity of these basins is about 1.5 gallons. One unique vessel of this ware is a very small thick-walled bottle (Fig. 1,j). Another is a thin-walled bottle of conventional shape.

Other artifacts of pottery include pipes, a bead and a ring. One pipe type has a tubular stem 5" long and $0.2813^{\prime \prime}$ in 


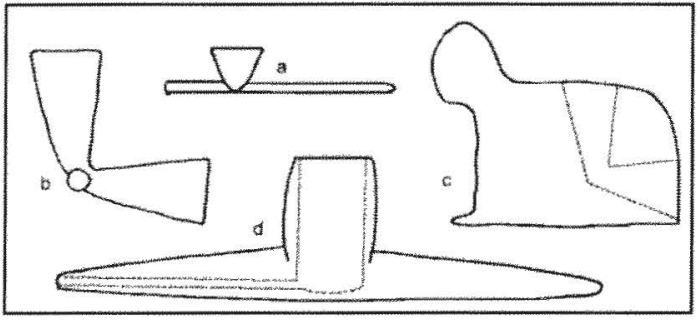

Figure 5. Pipes from the Norman site (34WG2). Not to scale.

diameter; one end is plugged. A flaring thin-walled bowl is attached $1.5^{\prime \prime}$ from the plugged end (Fig. 5, a). These pipes are made of a fine, shell tempered paste, highly burnished, similar to ware C. A pipe of ware B is the large "elbow" type (Fig. 5, b). The conical bowls, each 3" long and $1.375^{\prime \prime}$ in diameter at the orifice, are slightly flattened on top and bottom toward the elbow which has a small knob on either side. The single bead is barrelshaped, $0.75 "$ long and $0.5 "$ thick. This last specimen was unassociated in the mound fill.

Made of unfired red clay is an effigy-like

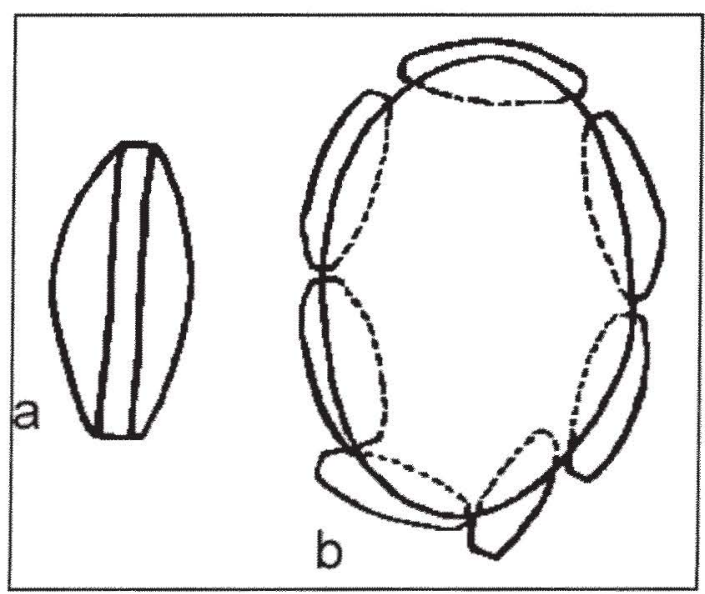

Figure 11. Unfired clay masses from the Norman site (34WG2). Not to scale. group consisting of a smoothed oblong mass about 15" long and 5" thick resting on a circle of seven green clay cylinders about 5 " long and 2" in diameter (Fig. 11, b). A green clay was used to make a unique cylinder, $4.5^{\prime \prime}$ long and $2.5^{\prime \prime}$ maximum diameter, with three longitudinal flutes (Fig. 11, a). Also of this material are flat discs 1' in diameter and 1" thick (Fig. 10, a \& b).

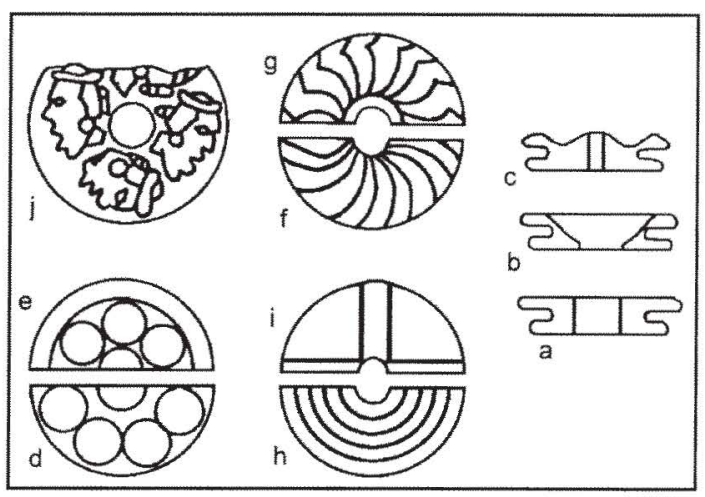

Figure 4. Earspools from the Norman site (34WG2). Not to scale.

GROUND STONE: This industry is limited to earplugs and pipes, executed in a fine-grained brown sandstone and a greenish sandy slate. Earplugs are the large pulley type; the face flanges range in diameter from $2.5^{\prime \prime}$ to $3.375^{\prime \prime}$, the back flange is slightly smaller. The face is either flat and generally embellished, concave or channeled (Fig. 4, a-c). The common incised designs are concentric circles, curved rays radiating from the center, and quadrants (Fig. 4, f-i). A relief decoration consists of a circle of six to eight knobs around a central knob (Fig. 4, 
d \& e). A thin plate of copper was frequently clamped to the face. The back is flat and undecorated. Incised on a single broken specimen in a unique design of four human profiles (Fig. 4, j). One set is carved from bauxite.

Pipes are the long double-stem type. The stem averages 12 " in length and 1.25 " in diameter near the center, tapers toward the ends, and is drilled through one arm only. The barrel-like bowl, $3 "$ deep and $1.75^{\prime \prime}$ in diameter inside, is near the middle of the stem (Fig. 5, d). A unique pipe of limestone is probably an effigy (Fig. 5, c). The surface has been so leached that no features are recognizable, but the general shape and style is similar to the effigy pipes from Spiro.

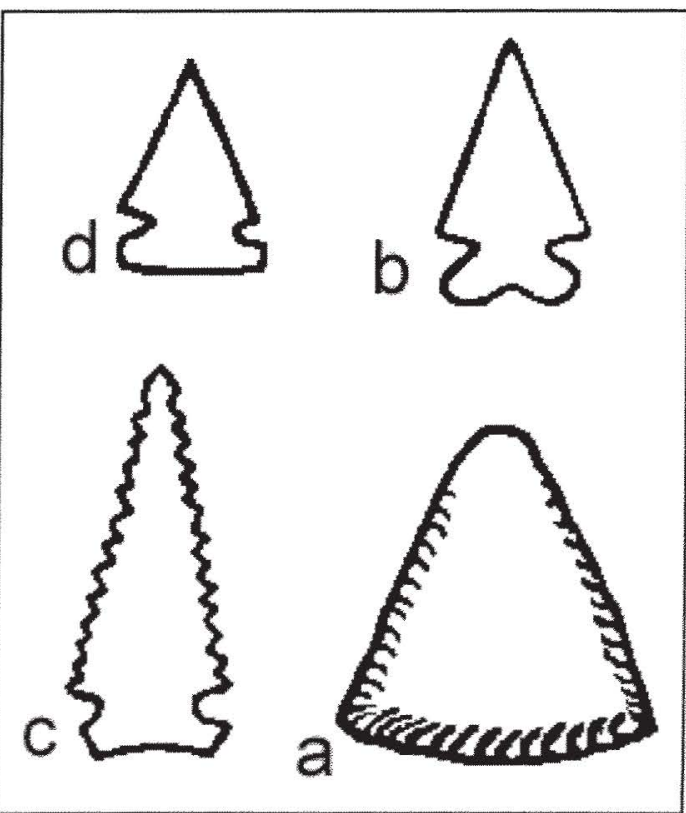

Figure 7. Some chipped stone artifacts from the Norman site (34WG2). Not to scale.

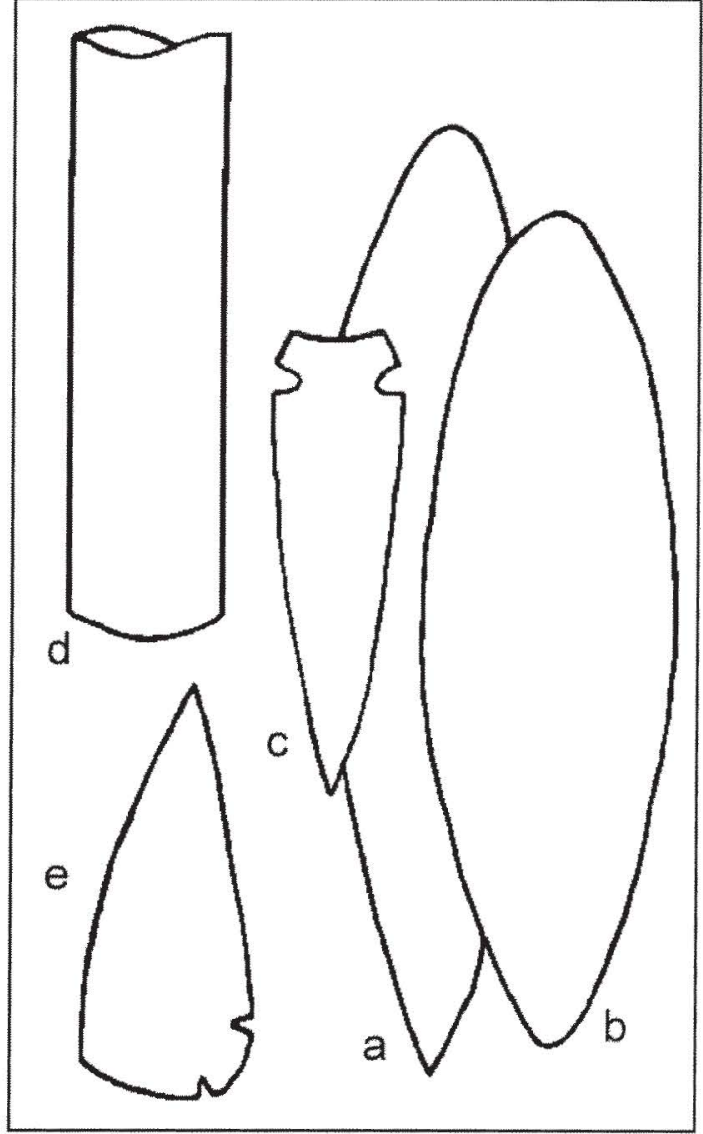

Figure 6. Some additional chipped stone artifacts from the Norman site (34WG2). Not to scale.

CHIPPED STONE: Chipped stone artifacts include projectile points, knife blade and scrapers. Points are of gray chert, range in length from $0.5625^{\prime \prime}$ to $1.6875^{\prime \prime}$ and are very thin. The shorter points are broad in comparison to the longer ones, and frequently are worked on one side only; the longer points are finely worked on both sides. There are three characteristic types: FsI, FsIII and Fr-III.*2 Found in most instances in bunches, each bunch is consistent in type. Three bunches of the longer points are serrated (Fig. 7, bd). A single large red flint point, 
associated with two knife blades, is 4.5" long and 1.25 " broad. Although of unusual size, it conforms to type FsIII (Fig. 6, c). Four other large hafted points were found in the mound fill. All were broken and none conformed to the typical shapes.

The two knife blades are of white chert, elliptical, 8.09375" and 9.1875" long and $2.375^{\prime \prime}$ and $2.25^{\prime \prime}$ broad respectively. Both are very thin, with very fine secondary chipping (Fig. 6, a \& b). A third blade, of gray chert, is smaller and cruder. There is also a unique corner-tanged blade of white chert 4" long (Fig. 6, e). In the midden was a long, parallel-sided brown chert blade $5.875^{\prime \prime}$ long and 1.5 " broad; one end is worked to a fine cutting edge, the other end is broken off (Fig. 6, d). Other scrapers are small, thin flakes, with secondary chipping along one edge.

COPPER: Copper was employed in making solid and sheet copper artifacts and in plating artifacts of stone and wood. Four breast plates are repousse eagle effigies; three are fragmentary but the

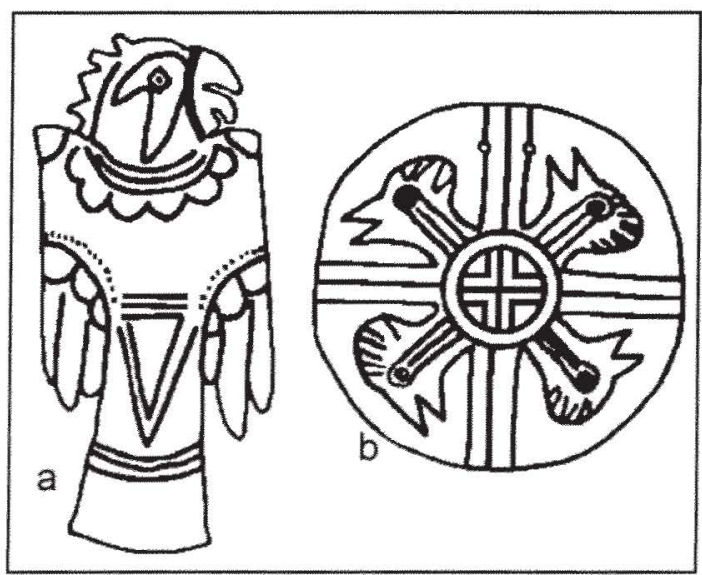

Figure 2. Copper plates from the Norman site (34WG2). Not to scale. fourth is $11.5^{\prime \prime}$ tall and $5^{\prime \prime}$ across the shoulders (Fig. 2, a). A fifth plate is roughly circular, $8.5^{\prime \prime}$ in diameter. The repousse design consists of a central Greek cross encircled by two concentric circles; the outer area is quartered, with a pileated woodpecker in each quadrant. Near the edges on one side are two small holes (Fig. 2, b).

Bodkin shafts are of 2 kinds: 1) solid copper, $0.3125^{\prime \prime}$ broad at the center and tapering to pointed ends, $0.09375^{\prime \prime}$ thick, and 17.5" and 16.5" long; and 2) c e d a r, circular in cross section and a veraging $0.1875^{\prime \prime}$ in diameter at the center, 12" in length and sheathed in a thin plate of copper. These shafts have artistically carved cedar

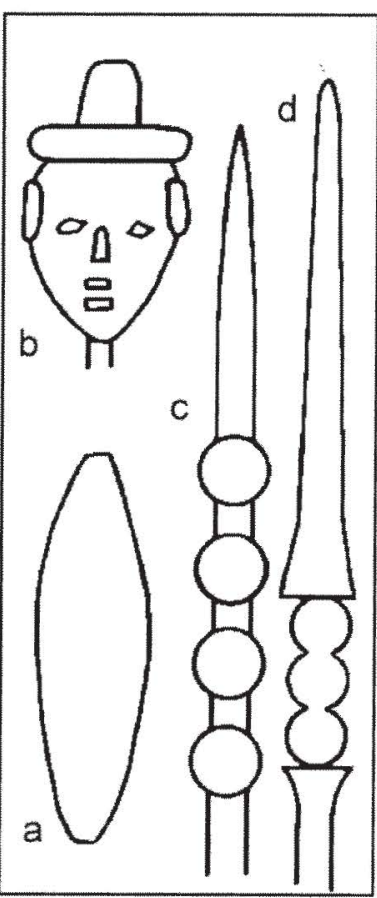

Figure 3. Copper
"bodkins" and beads from the Norman site (34WG2). Not to scale. heads, the most

elaborate being a small human-head effigy; others are three and four balls and a long thin point (Fig. 3, b-d). An awl or pin of solid copper is 5 " long and $0.1875^{\prime \prime}$ square in cross-section.

Six large beads made of cedar were 
encased in a thin plate of copper. They are $2.25^{\prime \prime}$ long and $0.5^{\prime \prime}$ in cross section at the center, tapering toward the ends (Fig. 3, a). One specimen appears to be the remains of a small cedar earplug which also had been encased in copper.

SHELL: A small, thin piece of engraved mussel shell may have been a gorget or pendant. The design is a heterogeneous combination of geometric elements (Fig. 9). A small number of spherical shell beads and pierced pearls were beigabe with several burials. Peals were large, the largest being $0.5^{\prime \prime}$ in diameter. Shell beads

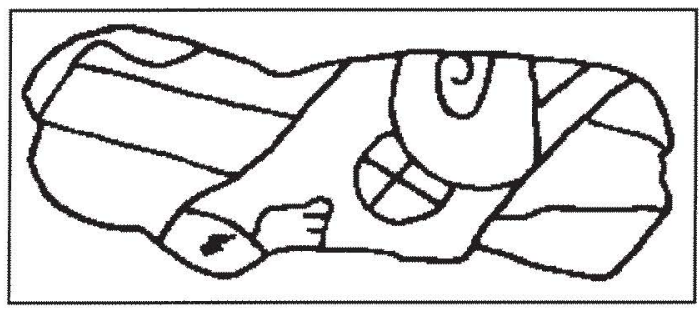

Figure 9. Engraved shell fragment from the Norman site (34WG2). Not to scale.

were fairly uniformly $0.25^{\prime \prime}$ in diameter, with the exception of one which was $0.75^{\prime \prime}$ long and barrel-shaped. Several unworked clam shells accompanied one burial.

MISCELLANEOUS: Small quantities of paint were deposited with several burials and scattered throughout Mound I; these include shades of red, yellow and brown. There were also deposits of the green putty-like material mentioned above which might have been used as pigment. Significant in connection with pigments is the presence of a block of sandy limestone, rectangular with rounded comers, $3.5^{\prime \prime}$ long by

$2.75^{\prime \prime}$ wide by 1.25 " thick. One face is flat and in the pores there yet remained traces of red ochre, suggesting its use as a mano for grinding paint. The opposite face is slightly concave.

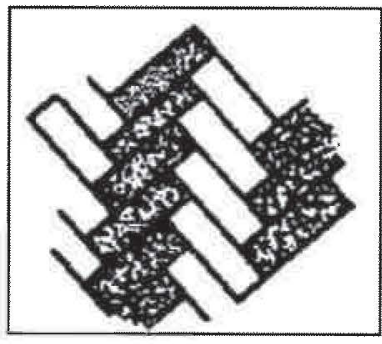

Figure 8. Twilled matting fragment from the Norman site (34WG2). Not to scale.

Several fragments of split cane matting were preserved through their contact with copper. The technique is twilled over three, under three. One specimen has one element bleached and the other stained (Fig. 8). Terrapin carapaces were placed in two jars. The miniature bottle contained seeds of a species of anise. Unassociated specimens in the mound fill include: an implement from the long bone of a large animal which, having a $0.5^{\prime \prime}$ square spatulate projection, could have been used equally well as a scraper, cutting edge, or awl; this specimen was just below the surface. Also just below the surface was a polished celt, almost circular in crosssection near the center, 5.5" long but broken at the blade end. One flat metate lay just below the surface; another, broken, was well within the body of Mound I; and two others were associated with stone cairns. Two chert nodules had a small highly polished area, that of 1 being so smooth that it reflects and image, and were undoubtedly used as polishing stones. A wedge-shaped core of white chert, 6" long and $1.5^{\prime \prime}$ thick, may have 
served as a crude axe as the broad end had been worked from one side to give a crude but effective cutting edge.

Beigabe distribution and associations and the interrelationships of the various artifact types as correlated with the burial types are indicated in the accompanying table. Burial 40 is an ideal burial, having in association all of the most recurring traits, excepting projectile points and the ware B jar. These traits, as indicated in the table, are: secondary disposition of the bone in a bundle, ware $\mathrm{A}$ jar, ware $\mathrm{C}$ bottle, ware D basin, copper plated stone earplugs, shell beads, copper breast plate and cane matting. Through their occurrence with two or more of these traits many of the traits in the total complex can be related to this combination. Thus, projectile points occur with ware $A$ jar, earplugs and bundle burial in two instances and with earplugs, shell beads and cane matting in one instance; the double-stem stone pipe occurs with earplugs, shell beads and cane matting and the double-stem clay pipes occur with the same combination; the clay effigy group occurs with ware $\mathrm{C}$ bottle, shell beads (1), and bundle burial. Detailed analysis of the specific elements of each trait might indicate some temporal change; gross observations suggest little if any.

\section{UNIT WgNr IV}

STRUCTURE HI: In the excavation to the north of Mound I-2 were uncovered the whole of one house feature, WgNr IV $\mathrm{H} 1$, and sections of several others (Fig. 12, a). Although there was no prepared floor associated with feature $\mathrm{H} 1$, it was evident that the structure was built on the original surface. This occupation level lay 1' beneath the surface at the north end of the excavation and 5 ' at the south end where it extended under the periphery of the mound; it was 13" above the clay subsoil. That the structure was several times repaired or partially rebuilt is evident from the three rows of post holes, $2^{\prime}$ apart, on the southeast side, the double row 1' apart, on the ends, and the single row of crowded post holes on the northwest side of the feature. Seven feet beyond the last mentioned row was a double row which extended almost the full length of the structure. The narrow room or corridor thus formed, however, was open at one end and only three irregularly placed post holes closed the other. The structure was 40 ' long; its width may have varied from 26 to $40^{\prime}$, depending on which set of post holes formed the side walls. Post holes were 3 " to 4 " apart, varied from 5 " to 12 " in diameter, and penetrated into subsoil 3" to $12 "$. Entrance way trenches near the center of the southeast side of the structure were associated definitely with the two inner walls and possibly with the outer wall. The entrances were $1.5^{\prime}$ wide and as much as 5.5' long. A single row of post holes extending partially across the southwest end of the structure partition off a section 9 ' wide. A similar partition may have extended across the other end of the house, but a subsequent storage pit had destroyed most of the evidence. There were several cache or storage pits within the structure. Pits C1, C2, C9, and C10 were oblong with sides and one end perpendicular and the other end slanting to a circular, flat bottom. They measured 4.5' to $7^{\prime}$ in length by $2.5^{\prime}$ to $3.5^{\prime}$ in width, and 


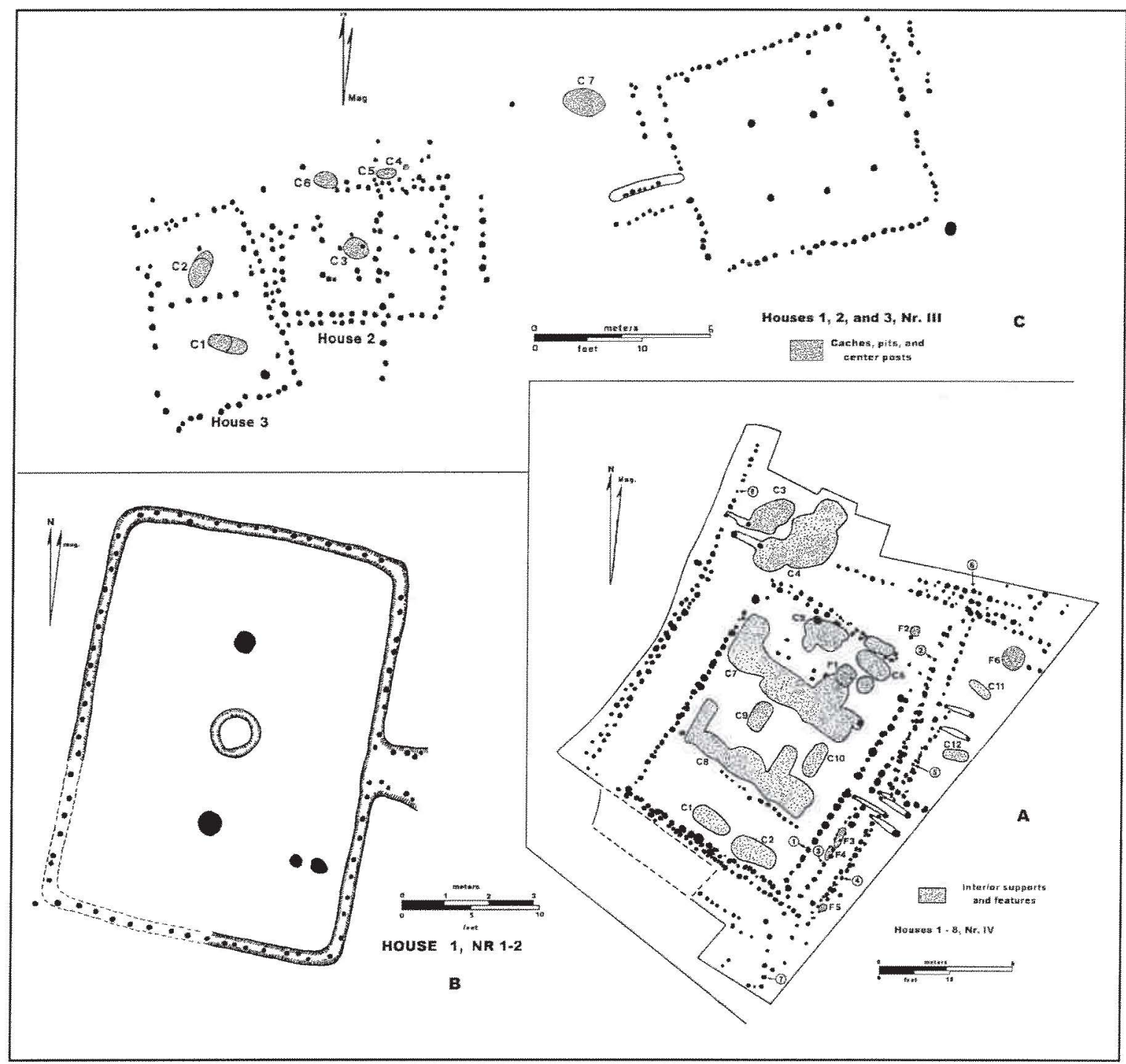

Figure 12. Houses excavated at the Norman site (34WG2), adapted from Finkelstein 1940.

extended into subsoil $24^{\prime \prime}$ to $30^{\prime \prime}$. (NOTE: The ground plan was drawn of pit outlines observed at the top of the subsoil, and depth measurements were made from the same plane. Consequently, pit outlines do not correspond exactly with the shape of the pits at their plane of origin; and $13^{\prime \prime}$ should be added to depth measurements of pits and post holes associated with feature
H1.) Features $\mathrm{C} 7$ and $\mathrm{C} 8$, composites of several of the simple oblong pits, also were undoubtedly associated with the structure; if, as stated above, the digging of $\mathrm{C} 7$ destroyed portions of a partition, then it may be assumed that these complex pits were coeval with a late period of occupation of the structure. There was no evidence of a fireplace associated with the 
structure. Small pellets of fired clay were occasionally found in the fill of post holes and storage pits, but in the absence of more evidence it is improbable that this was daub from the walls of a structure that had burned.

STRUCTURE H2: Two rows of post holes 2 ' apart cut across the east corner of structure H1. Two entrance way trenches extend eastward from the center of the east row. A single row extends westward from the north end, but there was no evidence of either the west or south wall. As the post holes were relatively small and shallow, the absence of the two walls would imply that the floor of the structure was at a higher level than $\mathrm{H} 1$ and the holes did not penetrate into subsoil. Position of fireplace F1 supports this conclusion. This feature, a flat $2^{\prime}$ square prepared clay fireplace with a hole near one side, was 21" above subsoil and had been disturbed somewhat by the plow. Position of pits C5 and C6 suggests possible association with this floor plan. They would have been exceptionally deep, however, as the circular appendages penetrated into subsoil 30 ".

Rows of post holes partially uncovered in the north end of the excavation indicate other structures at the original level of occupation, while post holes and thin sand-wash lines at the south end indicate occupation levels at $8 "$ and $10 "$ above the original occupation level.

Several fireplaces can be associated with these upper levels, but none with the lowest level. Fire pits F2 and F5 were 12" in diameter and 12" deep; F6 was 24" in diameter, 4" deep, has sloping walls and a flat bottom. Fire pits F3 and F4 were 24" long by 8 " wide; the sloping bottom as 12 " deep at the lower end. There was no evidence of floors with which they could be associated. All fire places contained clean ashes and bits of charcoal.

The irregularly shaped storage pits $\mathrm{C} 3$ and $\mathrm{C} 4$ penetrated into subsoil only 4 " and probably were associated with a late level of occupation. The position of small pits $\mathrm{C} 11$ and $\mathrm{C} 12$ suggest possibility they were outdoor pits associated with structure $\mathrm{H} 2$, but it was impossible to determine their level of origin.

There were practically no artifacts found in this excavation. On the floor of feature $\mathrm{C} 4$ were an oblong mano and broken metate. In the fill of feature $\mathrm{C} 12$ was the core of a broken earplug.

\section{REFUSE HEAP WgNr V}

A large refuse heap lies under the northeast periphery of Mound I-2 at a depth of about 1' above the original occupation level. One edge of this deposit was encountered in the southeast corner of the excavation. In final profile it extended northward about $30^{\prime}$, where it became a thin layer; to the west it pinched out at about $15^{\prime}$. At the center it was about $2^{\prime}$ deep. In the refuse were identified bones of deer, buffalo, rodents, birds and fish, and terrapin carapaces and clam shells. Two of the shells were perforated hoes. Although few sherds were found, all four wares are represented. 


\section{HOUSE FLOOR WgNr I-2 - H1}

Near the surface in the southwest quarter of Mound I-2 was a packed and smoothed clay floor, fired red, 29.5' long by $22^{\prime}$ wide, the major axis aligned north-south (Fig. 12, b). Extending completely around the outside of the feature was an embankment 3" high and 8" wide. Post holes within the outer edge of the embankment were, on the average, 4 " in diameter, 8 " to $16^{\prime \prime}$ in depth and spaced at 1 'intervals. Entrance way, 2.5 ' wide and at least $3^{\prime}$ long, was at the center of the east wall. Two central roof support posts were 2 ' in diameter and at least $2.5^{\prime}$ deep. The central fire basin was circular. It was banked to a height of $1 "$ above the floor making total depth 4". The diameter across the top was $30^{\prime \prime}$. The two post holes near the southeast corner of the floor apparently were associated with the structure.

Covering the floor were segments of charred poles 3" to 4 " in diameter, charred grass, cane and twigs, and clay daub. Lying on the floor beneath this material were a small piece of ground sandstone which might have been the pole end of a celt, a quantity of charred ragweed seeds, and a few beans resembling lima beans.

A 4" to 5" layer of unfired red clay lay directly on the charred material on the floor and extended indefinitely beyond the edge of the floor, indicating the floor was slightly below the level of the outside surface. Ground around the house within the $3^{\prime}$ wide area uncovered was clean of midden refuse; the walls of the burning structure had fallen inward so there was no burial material in this area.

The edges of the two other wattle covered prepared clay floors were encountered at lower levels in the profile of the trench in the west side of the mound. Neither was uncovered. A large mass of charred maize kernels, showing the imprint of the bottom of a coiled basket, was turned up on the edge of one of the floors.

\section{MOUND WgNr III}

The southern one-third of this large domicilliary mound was excavated. ${ }^{3}$ Confined to a portion of this area was an intrusive burial complex. House structures on this side of the mound were on and to about $1.5^{\prime}$ above the original surface. In a test trench into the west side of the mound there was evidence of a structure $3^{\prime}$ above the original level of occupation.

Floor $\mathrm{H} 3$, under the southeast periphery of the mound, was rectangular with rounded, open corners, 24 ' by 22 ', the major axis aligned approximately eastwest (Fig. 12, c) [note says $\mathrm{H} 1$ in fig. 12]. The 8 ' long entranceway was at the center of the west wall. The north wall posts of this passage were set in a $1^{\prime}$ deep trench. Two and one-half feet outside the house wall posts of the north half of the east and west walls was a gravel embankment into which had been set small posts slanting in toward the house. Four large central posts form a rectangle 6 ' east-west and $8^{\prime}$ northsouth. There were segments of charred posts and wattle on the fired prepared clay floor, but no daub. The north half of the floor was 3" above the gravel subsoil 
stratum but the south half lay directly on it. West of this house were two other structure outlines.

Owing to the unevenness of the floor it was difficult to determine the vertical position of Floor $\mathrm{H} 2$. It was later than Floor $\mathrm{H} 3$, sufficient time having elapsed between the building of the two structures for a considerable amount of debris to have leveled off the slightly westward dipping surface to the west of the earlier structure. The house was approximately $16^{\prime}$ square. Near the center was a circular cache pit $2.5^{\prime}$ in diameter. On the outside of the north wall were other cache pits, the level of origin of which could be exactly determined although they appeared to be coeval in time with the occupation level of the structure.

Floor $\mathrm{Hl}$ was just to the west of the preceding structure, but 1' of midden deposit separated the two levels of occupation. The floor was uneven and the wall outline was irregular. The structure was approximately $20^{\prime}$ by 14 '; a partition, open at 1 end, divided the house into 2 roughly rectangular rooms. In the center of each room was an ovoid pit, approximately 4 ' long by 2 ' wide, one end wall of which sloped to a flat, oval bottom. [note in margin: H3 in Fig. 13]

It was impossible to determine whether either of the two last described structures had an extended entrance; it was equally as difficult to determine which of the several breaks in the wall was the doorway. There were no prepared fireplaces in any of the structures. Thirty feet south of H3, and apparently on the same occupation level, were two groups of six stones 5' apart which undoubtedly served as hearths.

\section{HISTORICAL RECONSTRUCTION}

There was no time available in the laboratory to prepare an analytical interpretation of the Norman site material. A general treatment of the material indicates a homogeneity of the burial beigabe and the close relationship between this material and the material from the fill of the mounds and the midden. It is obvious from such a treatment of the material that, with the exception of the intrusive burial complex in Mound III, the units excavated constitute a single component. This observation together with the inference drawn from the several occupation levels and village areas which show a developmental sequence of house floor types are interpreted to imply a long occupation of the site by a single group, which, however, was probably influenced to some extent by an external but closely related culture.

This external influence undoubtedly came from one or more of several culture centers in northeastern Oklahoma which have presented a common material culture complex: the Reed site near Grove to the north, the Hughes site near Muskogee to the south, the Brackett site near Tahlequah to the east, and the Craig site near Spiro, the largest and most widely known, to the southeast. These components, including the Norman component, are constituents of the Spiro Aspect, Lower Mississippi Phase. The focus, or foci, have not yet been determined. 
Historical data shed little light on the tribal identity of the Spiro complex. It does suggest a temporal position, however, for it indicates the probable abandonment of the Spiro sites by the beginning of the period of French explorations down the Mississippi and probably their abandonment before De Soto's incursion west of the Mississippi. The evidence exists in the absence of references by the chroniclers of these periods to such a rich and highly sophisticated culture on the upper waters of the Arkansas River, and the absence of European material at all the sites of this group of highly efficient aboriginal traders.

There is some archaeological evidence indicating the historical identify of this complex. The Gahagan site on Red River in Red River County, La., fits bodily intothe Spiro Aspect. According to James A. Ford, the Gahagan site is early Caddoan culturally. It is a development of the early complex at the Crenshaw site, which is a lateral off-shoot of the Marksville sequence, branching off from the Troyville period. The Gahagan site is coeval in time with the latter part of the Coles Creek complex. ${ }^{* 4}$ It is evident that the Spiro Focus complex is similar if not identical to the culture out of which developed the Red River Caddo complex.

*2 For classification, see author's "A Suggested Projectile Point Classification", in American Antiquity, vol II, No. 3, 1937.

${ }^{* 3}$ This being the last unit on the site to be excavated, and the supervisor having been transferred before it was completed, the analyses of the midden material and burial complex were not completed. Consequently, only the description of the house floor patterns is presented at this time. A subsequent report will be released as soon as the necessary analyses have been made.

${ }^{* 4}$ Personal correspondence. We wish to express here our appreciation for the prompt and valuable response made by $\mathrm{Mr}$. Ford to personal inquiries concerning this problem. 